\title{
THE EFFECTS OF SBF CONDITIONS ON ENCAPSULATION OF AGAROSE GEL WITH HYDROXYAPATITE MICROCAPSULES
}

\author{
Hiroki Nakamura $^{1}$, Michiaki Sakaguchi ${ }^{2}$, Takeshi Yabutsuka ${ }^{1 *}$, Shigeomi Takai $^{1}$, \\ Takeshi $\mathrm{Yao}^{3,4}$ \\ (*Corresponding author: yabutsuka@energy.kyoto-u.ac.jp) \\ ${ }^{1}$ Graduate School of Energy Science, Kyoto University, Kyoto 606-8501 Japan \\ ${ }^{2}$ Faculty of Engineering, Kyoto University, Kyoto 606-8501 Japan \\ ${ }^{3}$ National Institute of Technology, Kagawa College, Takamatsu, Kagawa 761-8058 Japan \\ ${ }^{4}$ Institute of Advanced Energy, Kyoto University, Uji, Kyoto 611-0011 Japan
}

Keywords: Hydroxyapatite microcapsule, Biomimetic method, Simulated body fluid, Apatite Nucleus

Abstract: By raising the temperature or the $\mathrm{pH}$ of an acellular simulated body fluid (SBF), nanoparticles of amorphous calcium phosphate are precipitated. The nanoparticles are highly active to induce hydroxyapatite formation in body fluid or SBF. In this study, the authors fabricated hydroxyapatite microcapsules encapsulating an agarose gel by using the nanoparticles and examined the effects of the $\mathrm{pH}$ and the concentrations of SBF on the microcapsules formation process. Increase in ion concentrations or raising $\mathrm{pH}$ of $\mathrm{SBF}$ caused the acceleration of the microcapsules formation.

(Received January 4, 2016; Accepted March 24, 2016)

\section{INTRODUCTION}

Hydroxyapatite $\left(\mathrm{Ca}_{10}\left(\mathrm{PO}_{4}\right)_{6}(\mathrm{OH})_{2}\right)$, the major component of human bones and teeth, is the important bioceramic for medical engineering because of its high bioaffinity and non-toxicity to living bones ${ }^{1-4}$ and cells ${ }^{5,6}$. In addition, it also performs biopolymer adsorption ability such as a protein adsorption ${ }^{7}$.

The simulated body fluid (SBF) has inorganic ion concentrations nearly equal to those of human blood plasma ${ }^{8-10}$. This fluid is able to be useful to reproduce the reaction of bone-like hydroxyapatite formation in living body.

By raising the temperature or the $\mathrm{pH}$ of $\mathrm{SBF}$, nanoparticles of amorphous calcium phosphate are precipitated. Recently, we reported that the nanoparticles actively induce hydroxyapatite formation in SBF or in body fluid, and we named the particle apatite nucleus ${ }^{11,12}$

Previous experiments by our group have shown that several hydroxyapatite microcapsules were fabricated by using apatite nucleus ${ }^{13,14}$. The microcapsules encapsulating Ag microspheres possessed a sustained-release of $\mathrm{Ag}$ ion ${ }^{15}$. The sustained-release properties were also demonstrated in the case of encapsulating silica gel microspheres inducing insulin ${ }^{16}$ and agarose gels inducing vitamin $\mathrm{B}_{12}{ }^{17}$. The hydroxyapatite microcapsules encapsulating maghemite microparticles possessed a protein adsorption property and was able to be collected by magnetism of maghemite ${ }^{18}$. The microcapsules encapsulating plasmid DNA were successful in a gene transfer ${ }^{19,20}$.

Thus using apatite nucleus made it possible to fabricate various hydroxyapatite microcapsules in SBF. It is considered that the formation process of hydroxyapatite microcapsules is based on the following procedure. Firstly, apatite nuclei are attached to or included in microparticles. Secondary, the microparticles are soaked in SBF. The apatite nuclei on the surface of the microparticles encourage the formation of hydroxyapatite. Hydroxyapatite is induced on their surface in SBF, and the microcapsules are formed.

Although the fabrication of hydroxyapatite microcapsules was studied, the effects of SBF conditions on the formation of the microcapsules have not been examined. Generally, hydroxyapatite formation in an aqueous solution is affected by the $\mathrm{pH}$ values and the ion concentrations because these factors are closely related to the degree of supersaturation of the solution against hydroxyapatite. In this study, the $\mathrm{pH}$ or ion concentrations of SBF were changed and their effects on the formation of hydroxyapatite microcapsules encapsulating agarose gels was investigated. 


\section{MATERIALS AND METHODS}

Three types of SBF (NM-SBF, HP-SBF, HC-SBF) with the $\mathrm{pH}$ value and the ion composition shown in TABLE 1 were prepared in order to examine the effects of the $\mathrm{pH}$ and the ion concentration of SBFs. TABLE 2 shows the amount of volume of the regents dissolved in ultrapure water for preparation of each types of SBF. The reagent grade $\mathrm{NaCl}, \quad \mathrm{NaHCO}_{3}, \quad \mathrm{KCl}, \quad \mathrm{K}_{2} \mathrm{HPO}_{4} \cdot 3 \mathrm{H}_{2} \mathrm{O}$, $\mathrm{MgCl}_{2} \cdot 6 \mathrm{H}_{2} \mathrm{O}, \quad 1 \mathrm{M}-\mathrm{HCl}, \quad \mathrm{CaCl}_{2}, \mathrm{Na}_{2} \mathrm{SO}_{4}$ whose amount or volume is shown in TABLE 2 were dissolved in ultrapure water in order and transferred into a $1 \mathrm{~L}$ measuring flask. The $\mathrm{pH}$ value of SBFs shown in TABLE 1 was controlled by dissolving tris(hydroxymethyl)aminomethane.

TABLE 1 Ion concentrations of human blood plasma and SBFs

\begin{tabular}{|ccccc|}
\hline & \multicolumn{4}{c|}{ Ion concentrations / mM } \\
\cline { 2 - 5 } & $\begin{array}{c}\text { Human blood NM-SBF } \\
\text { plasma }\end{array}$ & $\begin{array}{c}\text { (normal) } \\
\text { (high } \\
\text { pH) }\end{array}$ & $\begin{array}{c}\text { HC-SBF } \\
\text { (high } \\
\text { conc. })\end{array}$ \\
\hline $\mathrm{Na}^{+}$ & 142.0 & 142.0 & 142.0 & 343.9 \\
$\mathrm{~K}^{+}$ & 5.0 & 5.0 & 5.0 & 15.0 \\
$\mathrm{Mg}^{2+}$ & 2.5 & 1.5 & 1.5 & 3.6 \\
$\mathrm{Ca}^{2+}$ & 1.5 & 2.5 & 2.5 & 7.5 \\
$\mathrm{Cl}^{-}$ & 103.0 & 147.8 & 147.8 & 359.6 \\
$\mathrm{HCO}_{3}{ }^{-}$ & 27.0 & 4.2 & 4.2 & 12.6 \\
$\mathrm{HPO}_{4}{ }^{2-}$ & 1.0 & 1.0 & 1.0 & 3.0 \\
$\mathrm{SO}_{4}{ }^{2-}$ & 0.5 & 0.5 & 0.5 & 1.5 \\
$\mathrm{pH}^{2-}$ & $7.20-7.40$ & 7.40 & 7.60 & 7.00 \\
$\left(36.5^{\circ} \mathrm{C}\right)$ & & & & \\
\hline
\end{tabular}

TABLE 2 Amounts of reagents for preparing $1 \mathrm{~L}$ of SBFs

\begin{tabular}{|cccc|}
\hline & \multicolumn{3}{c|}{ Amount / volume of reagents } \\
\cline { 2 - 4 } & $\begin{array}{c}\text { NM-SBF } \\
\text { (normal) }\end{array}$ & $\begin{array}{c}\text { HP-SBF } \\
\text { (high pH) }\end{array}$ & $\begin{array}{c}\text { HC-SBF } \\
\text { (high conc.) }\end{array}$ \\
\hline $\mathrm{NaCl}$ & $7.996 \mathrm{~g}$ & $7.996 \mathrm{~g}$ & $19.19 \mathrm{~g}$ \\
$\mathrm{NaHCO}$ & $0.350 \mathrm{~g}$ & $0.350 \mathrm{~g}$ & $1.050 \mathrm{~g}$ \\
$\mathrm{KCl}$ & $0.224 \mathrm{~g}$ & $0.224 \mathrm{~g}$ & $0.672 \mathrm{~g}$ \\
$\mathrm{~K}_{2} \mathrm{HPO}_{4} \cdot 3 \mathrm{H}_{2} \mathrm{O}$ & $0.228 \mathrm{~g}$ & $0.228 \mathrm{~g}$ & $0.684 \mathrm{~g}$ \\
$\mathrm{MgCl}_{2} \cdot 6 \mathrm{H}_{2} \mathrm{O}$ & $0.305 \mathrm{~g}$ & $0.305 \mathrm{~g}$ & $0.732 \mathrm{~g}$ \\
$1 \mathrm{M}-\mathrm{HCl}$ & $35 \mathrm{~mL}$ & $35 \mathrm{~mL}$ & $105 \mathrm{~mL}$ \\
$\mathrm{CaCl}_{2}$ & $0.278 \mathrm{~g}$ & $0.278 \mathrm{~g}$ & $0.834 \mathrm{~g}$ \\
$\mathrm{Na}_{2} \mathrm{SO}_{4}$ & $0.071 \mathrm{~g}$ & $0.071 \mathrm{~g}$ & $0.213 \mathrm{~g}$ \\
\hline
\end{tabular}

Apatite nucleus was prepared by raising the $\mathrm{pH}$ of NM-SBF to 8.60 dissolving tris(hydroxymethyl)aminomethane at $25.0{ }^{\circ} \mathrm{C}$. The precipitated apatite nuclei were collected by filtration using a nitrocellulose membrane filter (MF-Millipore, Millipore Corporation, USA) of $50 \mathrm{~nm}$ pore size.

Sixty $\mathrm{mg}$ of an agarose (Agarose H, Nippon Gene Co., Ltd., Tokyo, Japan) and $2 \mathrm{mg}$ of apatite nuclei were added in $10 \mathrm{~mL}$ of ultrapure water. The agarose was dissolved in the water by boiling in the microwave. Then apatite nuclei were dispersed in thus obtained agarose sol by ultrasonic vibration for 10 minutes at $38.0^{\circ} \mathrm{C}$. Each SBF (NM-SBF, HP-SBF, HC-SBF, $960 \mathrm{~mL}$ ) and the agarose sol containing apatite nuclei were mixed and dispersed by ultrasonic vibration again at $38.0{ }^{\circ} \mathrm{C}$. The mixed solution was rotated in an incubator at $36.5^{\circ} \mathrm{C}$.

Formed hydroxyapatite microcapsules were collected by filtration using a $300 \mathrm{~nm}$ nitrocellulose membrane filter (MF-Millipore, Millipore Corporation, USA). The obtained microcapsules were observed by scanning electron microscopy (SEM; SU6600, Hitachi High-Technologies, Japan) and analyzed by energy dispersive X-ray analysis (EDX; XFlash 5010, Bruker, Germany) and X-ray diffraction (XRD; the Ultima IV, Rigaku, Japan) with $\mathrm{Cu}-\mathrm{K} \alpha$ radiation.

The decrement of $\mathrm{Ca}$ and $\mathrm{P}$ concentrations associated with formation of hydroxyapatite microcapsules in HC-SBF was measured by inductively coupled plasma atomic emission spectroscopy (ICP; ICP-7510, Shimadzu, Japan).

\section{RESULTS AND DISCUSSION}

\subsection{The formation of microcapsules in NM-SBF}

By using NM-SBF, the hydroxyapatite microcapsules were formed within 7 days. FIGURE 1 (a) shows that the SEM micrograph of the hydroxyapatite microcapsules fabricated in NM-SBF. at low magnification. A number of spherical microcapsules were observed. FIGURE 1 (b) shows that at high magnification. It was observed that the microcapsule was constructed of flake-like crystallites which characterize bone-like apatite. It is considered that the apatite crystals were covered with the microparticles of agarose gels. FIGURE 1 (c) shows the result of EDX analysis of hydroxyapatite microcapsule. Peaks of $\mathrm{Ca}$ and $\mathrm{P}$, the constituents of the hydroxyapatite, were observed.

The results indicate that an agarose gel containing apatite nuclei induced hydroxyapatite and formed microcapsules within 7 days by using NM-SBF. 


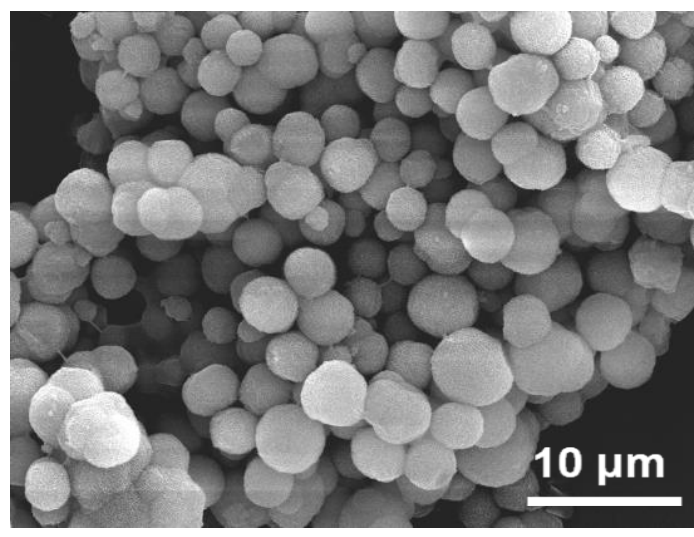

FIGURE 1 (a) The SEM micrograph of microcapsules by soaking in NM-SBF for 7 days at low magnification.

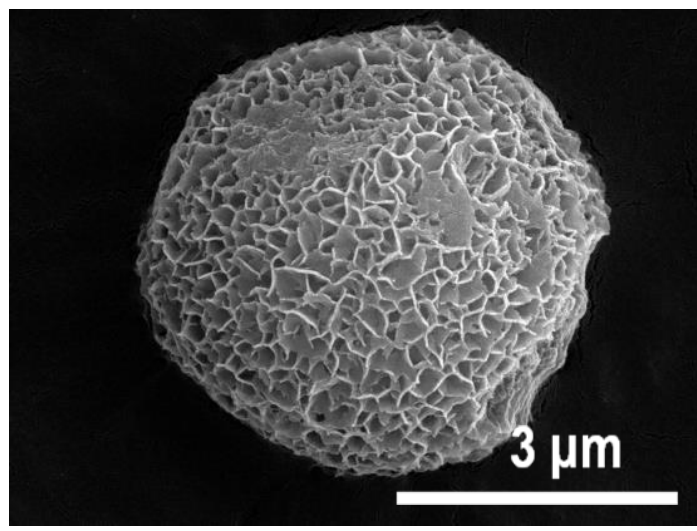

FIGURE 1 (b) The SEM micrograph of a microcapsule by soaking in NM-SBF for 7 days at high magnification.

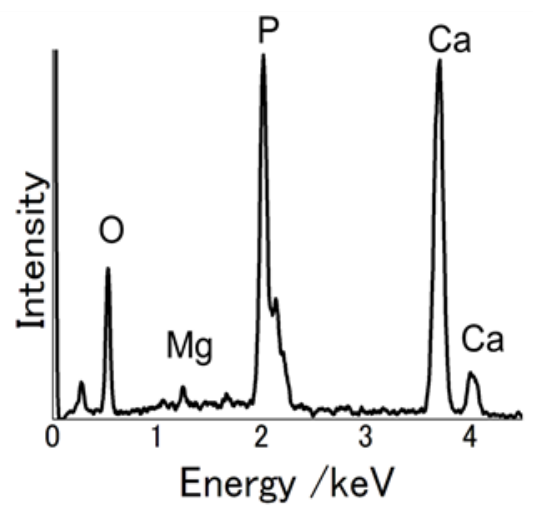

FIGURE 1 (c) The result of EDX analysis of hydroxyapatite microcapsules by soaking in NM-SBF for 7 days.
3.2. The formation of microcapsules in $\mathrm{HP}-\mathrm{SBF}$

By using HP-SBF, the microcapsules were formed within 2 days. In the SEM study, FIGURE 2 (a) and (b) were obtained. Spherical hydroxyapatite microcapsules were observed. FIGURE 2 (c) shows the result of EDX. Peaks of $\mathrm{Ca}$ and $\mathrm{P}$ were observed. The obtained results were similar to the 3.1. An agarose gel containing apatite nuclei induced hydroxyapatite in HP-SBF and formed microcapsules within 2 days.

These results indicate that raising $\mathrm{pH}$ of $\mathrm{SBF}$ promoted hydroxyapatite-forming reaction. The formation of hydroxyapatite in an aqueous solution can be described by the following equilibrium.

$$
10 \mathrm{Ca}^{2+}+6 \mathrm{PO}_{4}{ }^{3-}+2 \mathrm{OH}^{-} \leftrightarrow \mathrm{Ca}_{10}\left(\mathrm{PO}_{4}\right)_{6}(\mathrm{OH})_{2}
$$

Consequently, ionic activity product (IP) of hydroxyapatite is given by the following formula where $\alpha$ is the activity, $\gamma$ is the activity coefficient, and [ ] is the concentration of each ion.

$$
\begin{aligned}
\mathrm{IP}= & \left(\alpha \mathrm{Ca}^{2+}\right)^{10}\left(\alpha \mathrm{PO}_{4}{ }^{3-}\right)^{6}\left(\alpha \mathrm{OH}^{-}\right)^{2} \\
= & \left(\gamma \mathrm{Ca}^{2+}\right)^{10}\left(\gamma \mathrm{PO}_{4}{ }^{3-}\right)^{6}\left(\gamma \mathrm{OH}^{-}\right)^{2} \\
& \times\left[\mathrm{Ca}^{2+}\right]^{10}\left[\mathrm{PO}_{4}{ }^{3-}\right]^{6}\left[\mathrm{OH}^{-}\right]^{2}
\end{aligned}
$$

It is considered that IP was increased by raising $\left[\mathrm{OH}^{-}\right]$of SBF and the formation of microcapsules were accelerated.

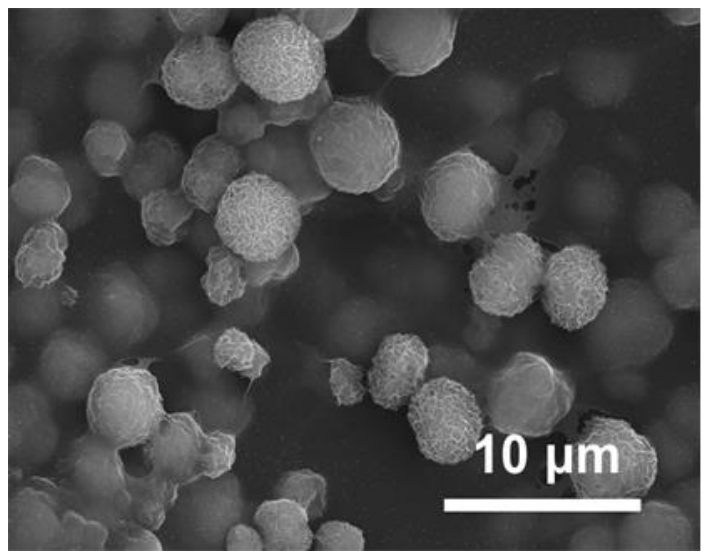

FIGURE 2 (a) The SEM micrograph of microcapsules by soaking in HP-SBF for 2 days at low magnification. 


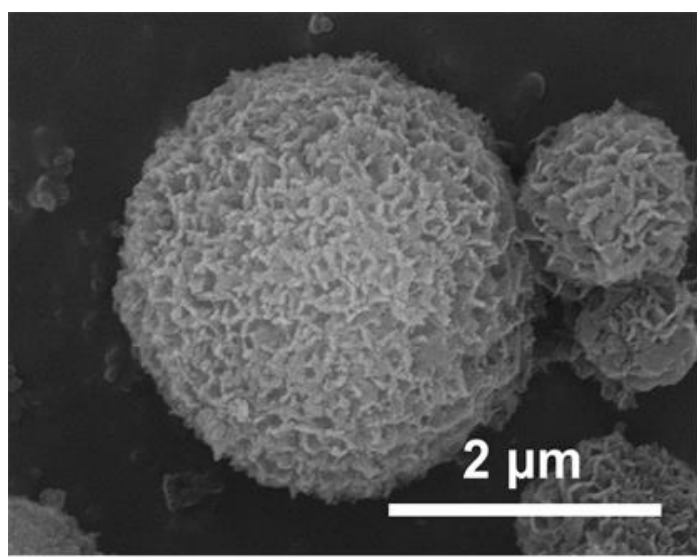

FIGURE 2 (b) The SEM micrograph of a microcapsule by soaking in HP-SBF for 2 days at high magnification.

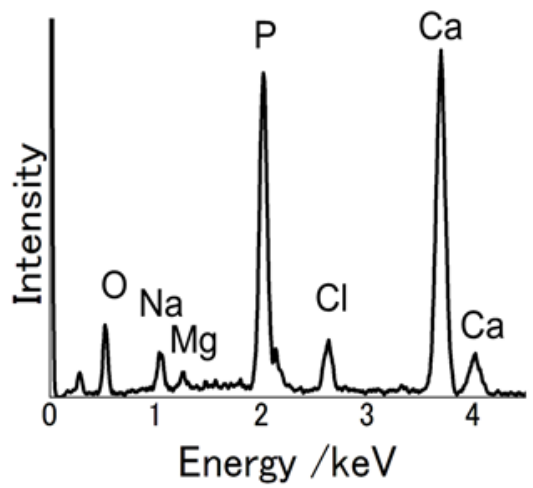

FIGURE 2 (c) The result of EDX analysis of hydroxyapatite microcapsules by soaking in HP-SBF for 2 days.

\subsection{The formation of microcapsules in $\mathrm{HC}-\mathrm{SBF}$}

By using HC-SBF, the microcapsules were formed within 2.5 hours. In the SEM study, FIGURE 3 (a) and (b) were obtained. FIGURE 3 (a) and (b) shows that hydroxyapatite microcapsules were observed. FIGURE 3 (c) shows that the result of EDX. Peaks of $\mathrm{Ca}$ and $\mathrm{P}$ were observed. The obtained results were similar to the 3.1. and 3.2. An agarose gel containing apatite nuclei induced hydroxyapatite in $\mathrm{HC}-\mathrm{SBF}$ and formed microcapsules within 2.5 hours.

These results indicate that raising ion concentrations of SBF promoted hydroxyapatite formation. The results suggested that increase in $\left[\mathrm{Ca}^{2+}\right]$ and $\left[\mathrm{PO}_{4}{ }^{3-}\right]$ caused the rise in IP by the Equations (1) and (2). Therefore, the degree of supersaturation against hydroxyapatite and ion collision frequency was increased. As a result, hydroxyapatite formation was accelerated.

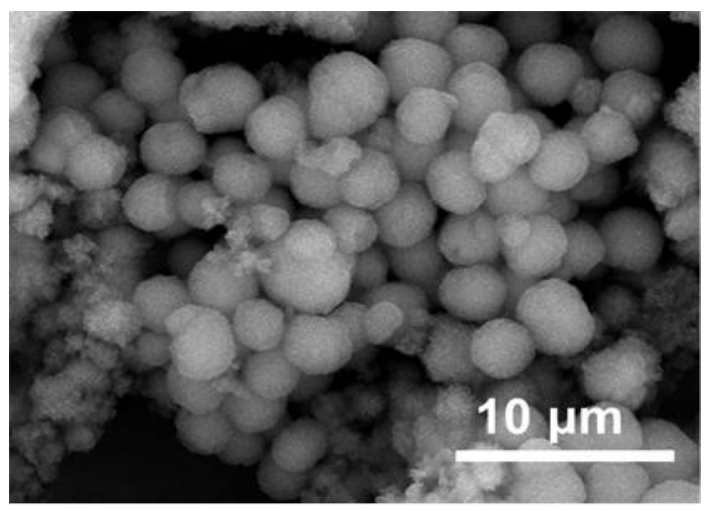

FIGURE 3 (a) The SEM micrograph of microcapsules by soaking in HC-SBF for 2.5 hours at low magnification.

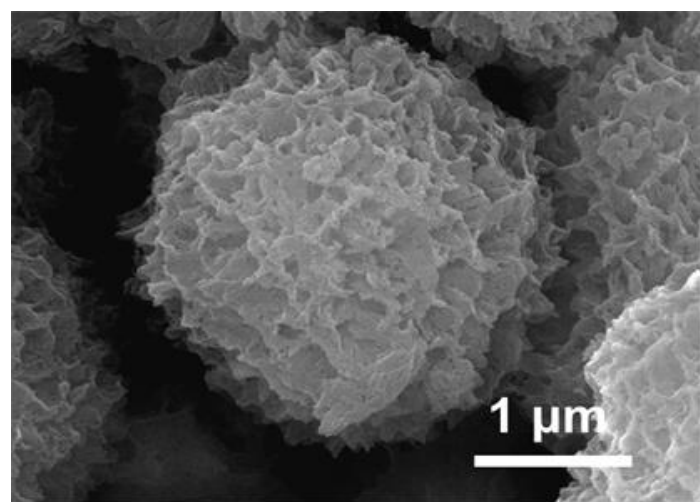

FIGURE 3 (b) The SEM micrograph of a microcapsule by soaking in HC-SBF for 2.5 hours at high magnification.

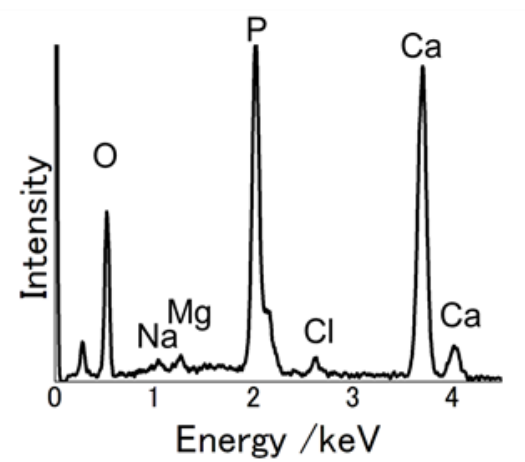

FIGURE 3 (c) The result of EDX analysis of hydroxyapatite microcapsules by soaking in HC-SBF for 2.5 hours. 
3.4. The XRD analysis of microcapsules by using each SBF

FIGURE 4 shows that the XRD patterns of the hydroxyapatite microcapsules by using NM-SBF, HP-SBF and HC-SBF. The blue squares represent the peak positions and intensity assigned to hydroxyapatite (JCPDS 24-0033). Not only the peak positions in the XRD pattern corresponded to hydroxyapatite, but broad peaks specific to bone-like apatite were observed for all conditions.

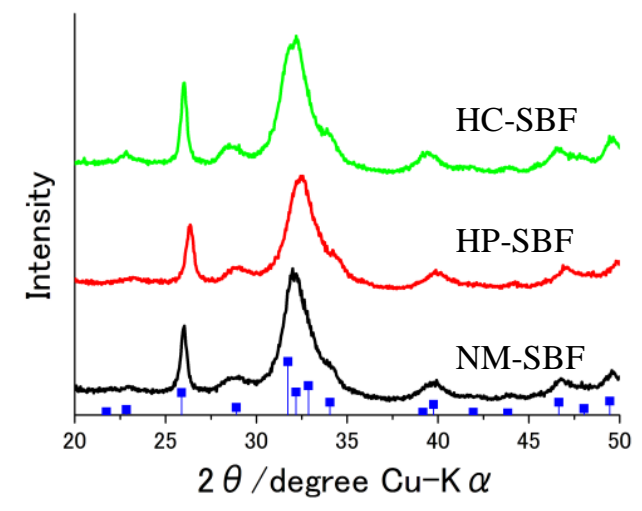

FIGURE 4 The XRD patterns of hydroxyapatite microcapsules by using each types of SBF.

\subsection{The formation period in $\mathrm{HC}-\mathrm{SBF}$}

FIGURE 5 shows that the concentration of $\mathrm{Ca}$ and $\mathrm{P}$ in HC-SBF during hydroxyapatite microcapsules formation. It is considered that the growth of hydroxyapatite microcapsules was almost completed for 3 hours. The concentrations hardly changed for the first hour. It appears that the formation of hydroxyapatite microcapsules were promoted in the SBF-hydroxyapatite microcapsules interface and therefore, the microcapsules were autocatalytically formed in the presence of the apatite nuclei. It is considered that the preferable formation period of hydroxyapatite microcapsules can be proposed from the results of ICP measurement.

\section{CONCLUSION}

The raising $\mathrm{pH}$ and ion concentrations of SBF accelerated the formation of hydroxyapatite microcapsules. The preferable formation period of hydroxyapatite microcapsules in $\mathrm{HC}-\mathrm{SBF}$ was estimated at 3 hours by ICP measurement. It was examined that the $\mathrm{pH}$ and the ion concentrations of SBFs affected the formation period of the hydroxyapatite microcapsules.

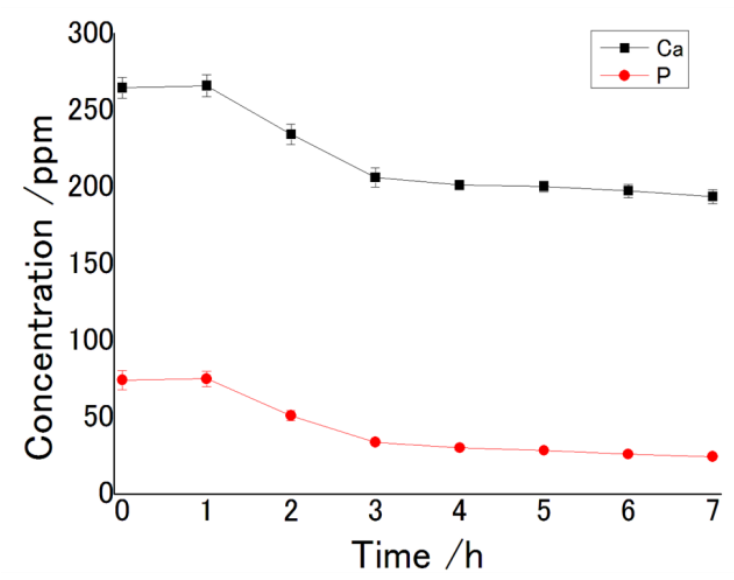

FIGURE 5 Changes in $\mathrm{Ca}$ and $\mathrm{P}$ concentrations in HC-SBF during hydroxyapatite formation.

\section{REFFERENCE}

1. R.Z. LeGeros, J.P. LeGeros, in An Introduction to Bioceramics, Edited by L.L. Hench(World Scientific, Singapore, 1993), Chap.9, pp. 139-180.

2. R.Z. LeGeros, J.P. LeGeros, in Bioceramics and their clinical applications, Edited by T. Kokubo (Woodhead Publishing, Cambridge, 2008), Chap.16, pp. 367-394.

3. M. Jarcho, J. F. Kay, K. I. Gumaer, R. H. Doremus, H. P. Drobeck, J. Bioeng., 1, 79 (1977).

4. H. Oonishi, H. Oonishi Jr. and S.C. Kim, in Bioceramics and their clinical applications, Edited by T. Kokubo(Woodhead Publishing, Cambridge, 2008), Chap.27, pp. 606-687.

5. D. D. Deligianni, N. D. Katsala, P. G. Koutsoukos, Y. F. Missirlis, Biomaterials., 22, 87 (2001).

6. S. C. Rizzi, D.J. Heath, A.G. Coombes, N. Bock, M. Textor, S. Downes, J. Biomed. Mater. Res., 55, 475 (2001).

7. A. Tiselius, S. Hjertén, Ö. Levin, Arch. Biochem. Biophys., 65, 132 (1956).

8. T. Kokubo, H. Takadama, Biomaterials., 27, 2907 (2006).

9. ISO/FDIS: 23317, International Organization for Standardization (2014).

10. T. Kokubo, H. Kushitani, S. Sakka, T. Kitsugi, T. 
Yamamuro, J. Biomed. Mater. Res., 24, 721 (1990).

11. T. Yao, M. Hibino, S. Yamaguchi, H. Okada, Japan Patent, No. 5261712 (2013).

12. T. Yao, M. Hibino, S. Yamaguchi and H. Okada, US Patent, No.8178066 (2012).

13. T. Yao, T. Yabutsuka, in Biomimetics, Learning from Nature, Edited by A. Mukherjee(Intech, Vukovar, 2010), Chap.27, pp. 273-288.

14. Y. Tabe, M. Hibino, T. Yao, Key Eng. Mater., 330-332, 1029 (2007).

15. T. Yabutsuka, S. Tsuboi, M. Hibino, T. Yao, Key Eng. Mater., 361-363, 1199 (2007).
16. S. Yamane, T. Yabutsuka, M. Hibino, T. Yao, Bioceramics., 22, 551 (2009).

17. T. Yabutsuka, K. Iwahashi, H. Nakamura, T. Yao, Key Eng. Mater., 631, 326 (2014).

18. Y. Tabe, M. Hibino, T. Yao, Key Eng. Mater., 587, 160 (2013)

19. T. Yao, T. Yabutsuka, S. Yamane, Y. Shimada, PCT Patent, PCT/JP2012/59689. (2012).

20. T. Yao, T. Yabutsuka, Y. Shimada, S. Kumazawa, H. Yawo, T. Ishizuka, S. Sakai, Extended Abstracts of The 13th Asian BioCeramics Symposium., 118 (2013). 